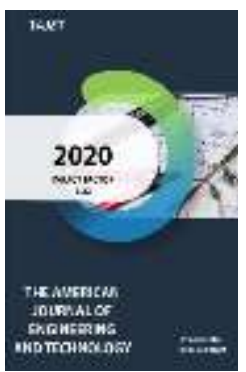

Journal Website: http://usajournalshub.c om/index,php/tajet

Copyright: Original content from this work may be used under the terms of the creative commons attributes 4.0 licence.

\section{Influence Of Polymeric Additives On The Corrosion} Resistance Of Concrete

\author{
N.I. Goncharova \\ Ferghana Polytechnic Institute, Ferghana, Uzbekistan
}

\section{Z.A. Abobakirova}

Ferghana Polytechnic Institute, Ferghana, Uzbekistan

\author{
A. Mukhamedzyanov \\ Ferghana Polytechnic Institute, Ferghana, Uzbekistan
}

\title{
ABSTRACT
}

The article presents data from experimental studies of the effect of polymer additives POLY - ANS on capillary absorption of concrete. It is shown that under the influence of POLY- ANS additives, the density, water tightness of concrete increases and hydrophobization of the walls of pores and capillaries is ensured (the wettability of concrete decreases) and, consequently, the corrosion resistance of concrete increases. It was found that for accelerated assessment of the degree of influence of POLY - ANS additives on the permeability of concrete, it is effective to use the criterion of a relative measure of hydrophobicity.

\section{KEYWORDS}

Capillary absorption, saline solutions, POLY - ANS polymer additive, pore hydrophobization, permeability, criterion of relative hydrophobicity measure, corrosion resistance.

\section{INTRODUCTION}

In world practice and in the republic, there is an urgent direction towards providing the construction industry with high-quality materials and structures, including those that increase the corrosion resistance of buildings, structures and its structures, especially under the conditions of salt aggression most significant for the republic. 
As is known, the corrosion resistance of concrete cement stone depends, on the one hand, on the chemical resistance of its components with respect to the aggressive agent (for example, SO2-4 - ion), and on the other hand, on the rate of penetration of the solution of this aggressor into cement stone [1].

The main role in ensuring high corrosion resistance of concrete and reinforced concrete underground structures of buildings and structures is played by the density or waterproofness of concrete. In dense concrete, an intensive influx of water is excluded, contributing to the development of metabolic reactions to corrosion.

The corrosion resistance of concrete is known to be associated with the capillary permeability of concrete. In this case, the capillary permeability of concrete depends on the consumption of cement, the parameters of the pore structure, the composition of the saline solution and the test conditions.

\section{MAIN PART}

A decrease in capillary permeability is achieved by increasing the number of closed pores and their hydrophobization, which is achieved by the introduction of chemical additives.

The degree of influence of chemical additives is determined by the mechanism of their action on the cement system and the pore structure of concrete.

Among water-soluble polymers, the most relevant from the point of view of protection against crystallization corrosion and exposure to a dry hot climate in the republic are polymer gel additives. These are stabilizing additives that reduce the stratification (stratification) of a concrete mixture by changing the viscosity of water. The degree of swelling of hydrogels in water is determined by the density of the polymer network specified in the synthesis process.

In our studies, we used a polymer additive - a polymer reagent POLY-ANS (stabilizing hydrolyzed polyacrylonitrile), produced on the basis of nitron fiber production wastes.

Experimental studies have been carried out to establish the effect of the dosage of POLY- ANS additives on capillary absorption.

As working salt solutions, highly concentrated solutions were taken:5,5\% $\mathrm{Na}_{2} \mathrm{SO}_{4} ; 2,5 \% \mathrm{Na}_{2} \mathrm{SO}_{4}+$ $5,5 \% \mathrm{NaCl} ; 5,5 \% \mathrm{Na}_{2} \mathrm{SO} 4+5,5 \% \mathrm{NaCl}$, close to natural compositions (mineralized groundwater in the regions of Central Asia and Kazakhstan is characterized mainly by sulfate and chloride aggressiveness with a content of $\mathrm{SO}_{2}-4$ ions ranging from 6000 to $37000 \mathrm{mg} / \mathrm{l}$ and Cl from 2000 to 37000 $\mathrm{mg} / \mathrm{l})$.

The content of POLY- ANS additives was taken respectively 0.01 (POLY-ANS 1); 0.02 (POLY-ANS 2); $0.04 \%$ (POLY-ANS 3) by weight of binder and volume of concrete. The capillary absorption of concrete was studied using the developed analytical method for a comparative assessment of the degree of influence of chemical additives on the capillary permeability of concrete [1]. The amount of aggressive solution absorbed by a concrete sample for a certain period of time $(\mathrm{Wbc}, \%)$ is taken as the capillary absorption indicator.

The criterion for assessing the structural defectiveness is the porosity of concrete samples.

According to the results of the experiments, it was found that the capillary absorption of concrete naturally increases as the composition of the saline solution becomes more complicated. This can be explained by a higher concentration of ions in sulfatechloride solutions and a relatively large accumulation of salts in the pores of concrete.

POLY- ANS admixtures reduce Wbc to the extent that they affect the reduction in water demand of the concrete mix, the parameters of the pore structure and the water resistance of concrete. 
According to the degree of reduction of $\mathrm{Wbc}$ of concrete, additives are arranged in the following decreasing row: POLY - ANS $3>$ POLY-ANS2> POLYANS 1.

The relative decrease in the concrete strength of concrete in comparison with the standard is $3.1 ; 1.6$ and 1.4 times, respectively. In this case, the preliminary cyclic temperature effect (taking into account the effect of a dry hot climate) on concrete samples with POLY- ANS additives hardly affects the capillary absorption of the saline solution and $\mathrm{Wbc}$ changes by 1.09; 1.1 and 1.12 times (Fig. 1).

6

5

4

3

2

1

0

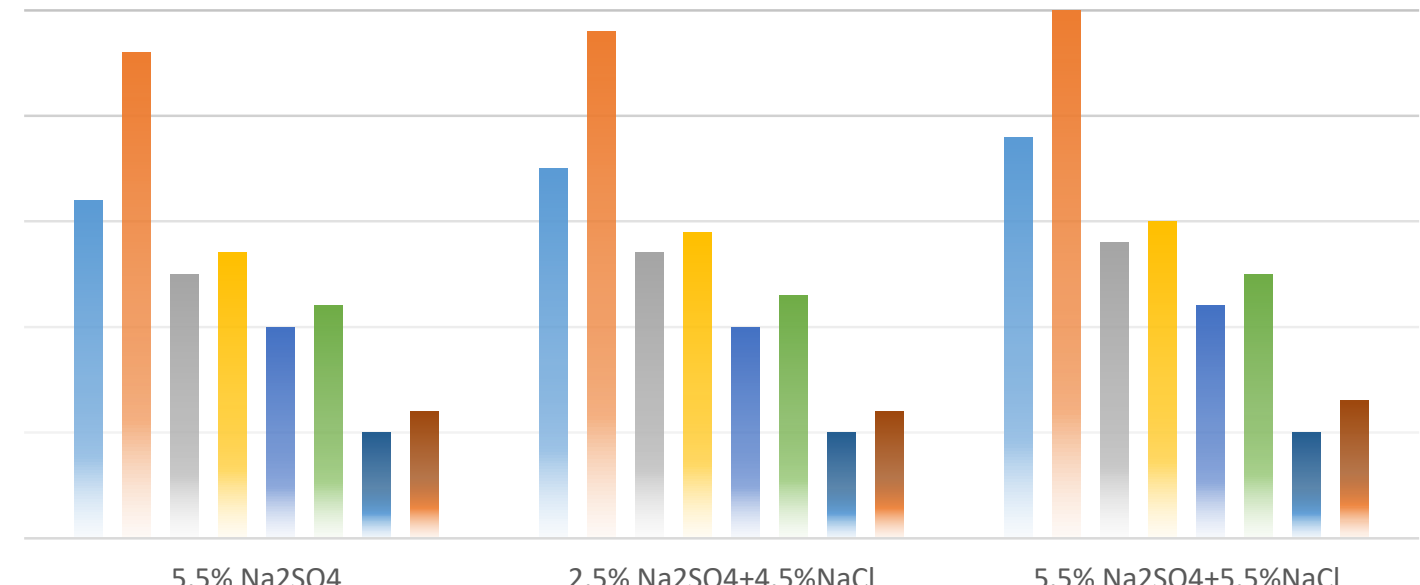

$5,5 \% \mathrm{Na} 2 \mathrm{SO} 4$

$2,5 \% \mathrm{Na} 2 \mathrm{SO} 4+4,5 \% \mathrm{NaCl}$

$5,5 \% \mathrm{Na} 2 \mathrm{SO} 4+5,5 \% \mathrm{NaCl}$

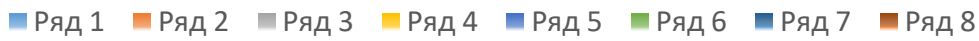

1,2 - reference concrete; 3,4,5,6,7,8 - concrete with additives respectively POLY- ANS1; POLY-ANS2; POLY-ANS 3; -normal hardening; -after a preliminary cycle. temperature exposure

Figure 1: Effect of POLY-ANS additives on capillary absorption

The established decrease in concrete water content $\mathrm{Wb}$ is due to the fact that under the influence of POLY - ANS additives, the density, water tightness of concrete increases and hydrophobization of pore walls and capillaries is ensured. Or, in other words, the wettability of concrete is reduced. As is known, the measure of wettability (Ms) is taken to be the value of $\cos \theta$ (contact angle of wetting) associated with surface tension at the interface of three interface surfaces adjacent to the wetting perimeter [3]:

$$
M_{\mathrm{c}}=\cos \theta=\frac{\sigma_{\mathrm{Tr}-\sigma_{\mathrm{TK}}}}{\sigma_{\text {жт }}}(1)
$$

To assess the hydrophobic properties of the concrete surface, this criterion is not acceptable, since the hydrophobicity can only be estimated in limited cases when: $\theta>90^{\circ}$.

In addition, the magnitude of the wetting measure in this case acquires a negative value. 
The concept is introduced - measures of hydrophobicity (Mg), which characterizes the hydrophobic properties of the concrete surface and is determined by the formula:

$$
\text { Мг }=1-\cos \theta \quad \text { или Мг }=1-\frac{\sigma_{\mathrm{Tr}-\sigma_{\mathrm{TЖ}}}}{\sigma_{\text {жт }}} \text { (2) }
$$

There is the following relationship between the hydrophobicity measure $(\mathrm{Mg})$ and the wetting measure (ms): $M g=1-m s(3)$

With regard to concrete surfaces, the determination of the hydrophobicity measure by formula (3) is difficult, since it is practically impossible to establish its components by known classical methods because of the porous structure of the material. Based on what is proposed an analytical method for calculating the hydrophobicity of concrete by capillary suction, which allows a comparative assessment of the influence of POLY - ANS additives and other formulation and technological factors on the change in the relative hydrophobicity taken by the formula:

$$
\mathrm{OM}_{\Gamma}^{\text {Д }}=1-\frac{\cos \theta^{\text {म }}}{\cos \theta^{\circ}}=1-\frac{\tan \varphi^{\text {म. }} r^{\circ}}{\tan \varphi \cdot r^{\text {म }}}
$$

Where $\tan \varphi^{\circ}$ - is the tangent of the slope of the line in coordinates $\frac{1}{\mathrm{H}}$;

$$
\frac{d H}{d \tau} \text { - for concrete without additives; }
$$

$\tan \varphi^{\text {म }} \quad$ is the same for concrete with admixture;

$r^{\circ}$ is the average radius of the capillaries of concrete without additives;

$r^{A}$ - the same as concrete with admixture.

The calculation results are shown in table1.

The values of the relative measure of hydrophobicity of concrete with POLY-ANS additives when testing samples for capillary absorption of saline solutions.

Табл.1

\begin{tabular}{|l|l|l|l|l|l|l|}
\hline \multirow{2}{*}{$\begin{array}{l}\text { Type of } \\
\text { additive }\end{array}$} & \multicolumn{3}{|l|}{$\begin{array}{l}\text { The average radius of pores } \\
\text { for concrete with cement } \\
\text { consumption, } \mathrm{kg} / \mathrm{m}^{3}\end{array}$} & $\begin{array}{l}\text { The values of the relative measure of } \\
\text { hydrophobicity of concrete with cement } \\
\text { consumption, kg / } \mathrm{m}^{3} \text { when tested in salt } \\
\text { solutions (the numerator is sulfate, the } \\
\text { denominator is sulfate-chloride }\end{array}$ \\
\cline { 2 - 7 } & 290 & 360 & 430 & 290 & 360 & 430 \\
\hline No additives & 96,5 & 92,4 & 90,8 & - & - & - \\
\hline POLY-ANS1 & 83,4 & 80,2 & 78,6 & $\frac{0,46}{0,61}$ & $\frac{0,50}{0,62}$ & $\frac{0,61}{0,65}$ \\
\hline POLY-ANS2 & 78,3 & 76,1 & 74,2 & $\frac{0,60}{0,70}$ & $\frac{0,67}{0,73}$ & $\frac{0,76}{0,78}$ \\
\hline POLY-ANS3 & 69,1 & 66,2 & 64,0 & $\frac{0,82}{0,89}$ & $\frac{0,87}{0,90}$ & $\frac{0,91}{0,93}$ \\
\hline
\end{tabular}


According to the table.1. [OM $]_{-}{ }^{\wedge} \mathrm{A}$ concrete with additives POLY - ANS 3 naturally increases with an increase in cement consumption and a decrease in the average radius of pores. That is, for an accelerated assessment of the degree of influence of POLY - ANS additives (and others) on the permeability of concrete, it is effective to use the criterion of a relative measure of hydrophobicity, which makes it possible to solve the problem relatively easily and with high accuracy.

\section{CONCLUSION}

Thus, according to the results of the studies, a positive effect of POLY-ANS additives on the capillary absorption of concrete was found. This is confirmed by data on a decrease in the water demand of the concrete mixture, water resistance of concrete, and improvement of the parameters of the pore structure, which indicates an increase in the corrosion resistance of concrete.

\section{REFERENCES}

1. Bartashevich A.A., Rud B.V., Putan L.A. To the mechanism of salt physical corrosion // Protection of building structures in aggressive environments of chemical and petrochemical industries / Sat. TsBTI., M. 1970, pp. 72-75.

2. Goncharova NI, Rakhmanov B. Properties of concrete with a polymer additive - waste production / Scientific and technical journal FerPI. Volume 22№2, 2018 p.149

3. Abobakirova Z.A. Abstract - Specialty 05.09.05- "Building materials and products" Topic: "Designing the composition and optimizing the properties of effective corrosion-resistant concrete with the addition of an ionic nature for underground structures" Fergana 2020., p. 48.

4. Mikhalchuk P.A., Ryabchun S.A. The nature and rate of corrosion destruction of concrete under conditions of capillary suction and evaporation of highly mineralized media // Sb.tr./ NIIZHB, M.1988, p.20-28

5. www.portol.spp ru / city / index.pht / 2 . 